\title{
Public acceptability of a sugar-sweetened beverage tax and its associated factors in the Netherlands
}

\author{
Michelle Eykelenboom* $\odot$, Maartje M van Stralen, Margreet R Olthof, Carry M Renders \\ and Ingrid HM Steenhuis on behalf of the PEN Consortium \\ Department of Health Sciences, Faculty of Science, Amsterdam Public Health Research Institute, Vrije Universiteit \\ Amsterdam, $1081 \mathrm{HV}$ Amsterdam, the Netherlands
}

Submitted 5 November 2019: Final revision received 6 April 2020: Accepted 21 April 2020: First published online 4 June 2020

\begin{abstract}
Objective: To investigate the level of public acceptability of a sugar-sweetened beverage (SSB) tax and its associated factors.

Design: Participants completed an online self-administered questionnaire. Acceptability of an SSB tax was measured on a seven-point Likert scale (strongly disagree to strongly agree). Associations between acceptability and sociodemographic factors, weight status, SSB consumption and beliefs about effectiveness (e.g., 'An SSB tax would reduce people's SSB consumption'), appropriateness, socioeconomic and economic benefit, implementation and trust were assessed using multivariable linear regression analyses.

Setting: The Netherlands.

Participants: Dutch adults aged $\geq 18$ years representative of the Dutch population for age, sex, education level and location ( $n$ 500).

Results: Of the participants, $40 \%$ supported and $43 \%$ opposed an SSB tax in general. Moreover, $42 \%$ supported ( $43 \%$ opposed) an SSB tax as a strategy to reduce overweight, and $55 \%$ supported (32\% opposed) an SSB tax if revenue is used for health initiatives. Participants with a low education level $(B=-0 \cdot 82,95 \% \mathrm{CI}-1 \cdot 31$, $-0 \cdot 32)$, overweight $(B=-0.49,95 \% \mathrm{CI}-0 \cdot 89,-0 \cdot 09)$, moderate or high SSB consumption $(B=-0.86,95 \% \mathrm{CI}-1.30,-0.43$ and $B=-1.01,95 \% \mathrm{CI}-1.47,-0.56$, respectively) and households with adolescents $(B=-0.57,95 \% \mathrm{CI}-1 \cdot 09,-0.05)$ reported a lower acceptability of an SSB tax than their counterparts. Beliefs about effectiveness, appropriateness, socioeconomic and economic benefit, implementation and trust were associated with acceptability $(P<0.001)$.

Conclusions: Public acceptability of an SSB tax tends to be higher if revenue is used for health initiatives. The factors associated with acceptability should be taken into consideration.
\end{abstract}

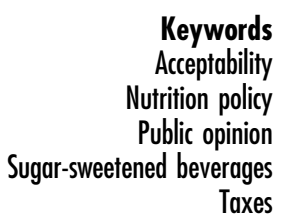

Keywords Acceprability

Public opinion Taxes
The prevalence of obesity is increasing worldwide ${ }^{(1)}$. Obesity is a significant risk factor for developing non-communicable diseases such as type 2 diabetes mellitus, CVD, musculoskeletal disorders and some types of cancer ${ }^{(1)}$. Obesity is a complex condition that is caused by many factors ${ }^{(2)}$. Among the dietary determinants, the consumption of sugar-sweetened beverages (SSB) has been recognised as a suitable target for obesity prevention interventions ${ }^{(3-5)}$. There is compelling evidence that consumption of SSB is causally related to weight gain and that reducing SSB consumption decreases weight gain among children and adults ${ }^{(3-5)}$. Mechanisms include their high levels of added sugar, low satiety and an incomplete compensatory reduction in energy intake at subsequent meals $^{(3-5)}$. In addition, SSB provide almost no nutritional value $^{(3-5)}$. Evidence supporting the association between SSB consumption and weight gain is stronger than for any other single type of food or beverage ${ }^{(5)}$. Various interventions have been developed to reduce the consumption of $\mathrm{SSB}^{(6)}$. In recent years, SSB taxation has received considerable attention as a feasible fiscal measure to implement ${ }^{(7)}$.

The effectiveness of SSB taxation in reducing SSB purchases and consumption is supported by growing evidence ${ }^{(7-12)}$. Furthermore, according to modelling studies, an SSB tax of 10-20\% could decrease the prevalence of overweight and obesity on a population level ${ }^{(13-18)}$. For example, one modelling study has found that the 
prevalence of obesity in the German population aged $15-$ 79 years could decrease by approximately $4 \%$ given a $20 \%$ SSB tax fully passed on to consumers ${ }^{(17)}$. The Commission on Ending Childhood Obesity of the WHO states the rationale for an SSB tax is strong and supported by the available evidence and therefore recommends governments to implement an SSB tax as a component of 'a comprehensive, integrated package of interventions that address the obesogenic environment' ${ }^{(7)}$. Over forty countries worldwide have enacted taxes on SSB to date, including a $10 \%$ excise tax on SSB in Mexico and a tiered excise tax applying different rates depending on the sugar content of beverages in the $\mathrm{UK}^{(19)}$. However, other countries have not yet introduced such a policy, for example, the Netherlands.

Although evidence of the effectiveness of SSB taxation is an important consideration for governments in the decision-making process, the extent to which an SSB tax is likely to be acceptable to the public is also affecting its agenda-setting, formulation, adoption and implementation $^{(20)}$. Quantitative and qualitative literature on public acceptability of an SSB tax has been synthesised in a recently conducted mixed-method systematic review ${ }^{(21)}$. Results of the meta-analysis of this review indicated that less than half ( $42 \%$ ) of the public supports an SSB tax based on studies conducted in the USA, Australia, the UK and France, ranging from $27 \%$ among registered Texan voters to $55 \%$ among a nationally representative sample of Australian adults ${ }^{(22,23)}$. As public acceptability of an SSB tax varies across countries because of different political, economic and sociocultural contexts, there is a need for studies in a wide range of countries ${ }^{(21)}$.

Within countries, several factors at the individual level seem to be associated with public acceptability of an SSB tax ${ }^{(23-32)}$. For example, previous studies indicated $\operatorname{age}^{(23,25-27,30,31)}, \operatorname{sex}^{(23,24,29,30)}$, education level ${ }^{(23-27)}$, weight status $^{(26)}$ and SSB consumption ${ }^{(24)}$ to be associated with public acceptability of an SSB tax. Public acceptability may also depend on public beliefs towards SSB taxation, such as beliefs about effectiveness and cost-effectiveness, appropriateness, economic and socioeconomic benefit, policy adoption and implementation, and mistrust of the industry, government and public health experts ${ }^{(21)}$.

To date, no studies have been conducted in the Netherlands to investigate public acceptability of an SSB tax. In the Netherlands, $50 \%$ of adults and $13 \%$ of children have overweight or obesity ${ }^{(33)}$. SSB consumption in the Netherlands is particularly high among children ${ }^{(34)}$. The most recent results from the National Food Consumption Survey (2012-2016) demonstrate that children consume on average $620 \mathrm{ml}$ of SSB per day ${ }^{(34)}$. Although declines in consumption levels have been reported over this period, SSB continue to contribute to a significant proportion (23.6\%) of added sugar intake among both Dutch children and adults ${ }^{(34)}$. Therefore, several stakeholders (e.g., consumer/health organisations, health professional associations and scientists) have previously argued for an SSB tax. In 2016, one parliamentary party adopted an SSB tax in its draft election programme. The tax proposal was, however, withdrawn during their election congress because the majority of their party members voted against the tax. Furthermore, no SSB tax has been included in the National Prevention Agreement presented by the Dutch government in collaboration with public and private organisations $^{(35)}$. Currently, the Netherlands has a valueadded tax rate of $9 \%$ that applies to all food and beverages ${ }^{(36)}$. In addition, consumer tax is payable on fruit and vegetable juices, soft drinks and mineral water, with no distinction made between SSB and sugar-free beverages (e.g., water or non-energetic sweetened beverages) ${ }^{(37)}$.

In the current study, an online survey was conducted to investigate public acceptability of an SSB tax in the Netherlands. Specifically, we intended to: (i) determine the level of public acceptability of an SSB tax, and (ii) assess the associations between public acceptability of an SSB tax and sociodemographic factors, weight status, SSB consumption and beliefs about effectiveness, appropriateness, economic and socioeconomic benefit, policy adoption and implementation, and trust of the industry, government and public health experts.

\section{Methods}

\section{Study design and participants}

This online survey was conducted in March 2019 using a data collection agency (Panel Inzicht), which maintains an online panel of 114.540 Dutch members aged $\geq 18$ years. Panel members are invited to participate in about one online survey per month, and survey participation is rewarded with various incentives (e.g., member points that can be redeemed for cash).

All panel members met the inclusion criteria of the current study (i.e., living in the Netherlands, Dutch speaking and $\geq 18$ years old). A stratified sampling method was used to ensure that the sample was nationally representative for age, sex, education level and location. By applying quotas based on the distribution of those variables within the Dutch population using data from the national statistical office, Statistics Netherlands (CBS) ${ }^{(38)}$, random subsamples of panel members were sent an e-mail invitation to participate with a link to the online questionnaire. For the age quotas, age was classified into the following categories: 18-24, 25-34, 35-44, 45-54, 55-64 and $\geq 65$ years. Education level was based on the highest qualification attained and classified into three levels based on the standard classification from the $\mathrm{CBS}^{(38)}$ : low (less than secondary school or higher secondary school certificate), middle (higher secondary school certificate) and high (technical college or university degree). Location was based on province and classified into four regions (i.e., North, East, South and West) based on the standard classification from the $\mathrm{CBS}^{(38)}$. The survey was run over $8 \mathrm{~d}$ 
until the agreed number of 500 completes was achieved. A total of 7069 panel members were invited to participate in the survey. The survey response rate was $7 \cdot 1 \%$.

\section{Measures}

Data were collected on the acceptability of an SSB tax, sociodemographic factors, weight status, SSB consumption and beliefs by means of an online self-administered Dutch questionnaire (see online supplementary material, Supplemental Table S1). The questionnaire was developed in Dutch language proficiency level $\mathrm{B}^{(39)}$, which is understood by the vast majority of the population. The questionnaire was pilot-tested on a heterogeneous target population of Dutch adults aged 22-79 years $(n 16)$ who were asked for feedback on the structure and phrasing of questions as well as the online procedure and layout using the thinking-aloud method. Based on the feedback, we clarified terms that were unclear to some participants (e.g., experts and societal health programmes). In addition, small adjustments were made to the layout of the questionnaire (e.g., we changed the colour of the progress bar from red to black, because several participants associated a red progress bar with making mistakes).

\section{Acceptability of an SSB tax}

Differences in the intended objective of the tax may affect the acceptability of an SSB $\operatorname{tax}^{(21)}$. Therefore, the acceptability of an SSB tax was assessed using three questionnaire items: 'I support imposing an SSB tax in the Netherlands', 'I support imposing an SSB tax in the Netherlands as a strategy to reduce overweight' and 'I support imposing an SSB tax in the Netherlands if revenue is used for health initiatives'. Items were all positively phrased in the active voice to improve readability, and responses were indicated on a seven-point Likert scale ranging from 'strongly disagree' (1), 'disagree' (2), 'slightly disagree' (3), 'not disagree, not agree' (4), 'slightly agree' (5), 'agree' (6) to 'strongly agree' (7). For the descriptive statistics, the variables were grouped into three categories: 'disagree' (response options 1-3), 'neither' (response option 4) and 'agree' (response options 5-7).

\section{Sociodemographic factors and weight status}

Data were collected on age, sex, education level, location, household composition, grocery responsibility, employment status, body height and weight. Age was categorised into '18-24 years', '25-54 years' and ' $\geq 55$ years'. Household composition was categorised into 'one or more children aged $0-13$ years living at home', 'one or more adolescents aged 14-18 years living at home' (including the response options 'one or more adolescents aged 14-18 years living at home' and 'both children and adolescents living at home') and 'no children or adolescents living at home' (including the response options 'no children or adolescents' and 'no children or adolescents living at home'). Grocery responsibility was categorised into 'not responsible', 'partly responsible' and 'largely/totally responsible' (including the response options 'largely responsible' and 'totally responsible'). Employment status was categorised into 'employed' and 'unemployed' (including the response options 'unemployed', 'retired', 'student' and 'other'). Self-reported BMI was calculated as weight $(\mathrm{kg}) /$ height $(\mathrm{m})^{2}$.

\section{SSB consumption}

To assess SSB consumption, participants were asked about their consumption of four SSB groups: regular soft drinks, fruit drinks and juices with added sugars, energy drinks and sport drinks with added sugars, and flavoured water with added sugars. The questionnaire included items adopted from the Dutch version of the FFQ that was designed for the HELIUS study to collect information about the frequency (e.g., 'during the past four weeks, how often did you drink regular soft drinks?') and the amount (e.g., 'how many glasses $(200 \mathrm{ml})$ of regular soft drinks did you drink on these days?') of intake of these beverages ${ }^{(40)}$. Examples of popular beverages were selected to clarify each SSB group using the most recent results from the National Food Consumption Survey for adults (20122016) ${ }^{(34)}$. Total SSB consumption was calculated as the sum of the four SSB groups and expressed in number of glasses consumed per week. Based on the currently enacted SSB taxes ${ }^{(19)}$, SSB consumption excluded water, artificially sweetened drinks, hot tea and coffee, concentrates, $100 \%$ fruit or vegetable juice and milk-based beverages.

\section{Beliefs}

Beliefs that appeared to have implications for the acceptability of an SSB tax in previously conducted qualitative studies were assessed using questionnaire items that were developed based on themes and subthemes that derived from the thematic synthesis of a mixed-method systematic review $^{(21)}$. Questionnaire items included beliefs about the following themes: (i) effectiveness and cost-effectiveness (e.g., 'I believe that an SSB tax would contribute to improving people's health'), (ii) appropriateness (e.g., 'I believe that SSB consumption contributes to the development of overweight'), (iii) economic and socioeconomic benefit (e.g., 'I believe that an SSB tax is not fair for those with a low income'), (iv) policy adoption and implementation (e.g., 'I believe that an SSB tax is feasible to implement in the Netherlands'), and (v) trust of the industry, government and public health experts (e.g., 'I trust that the government views an SSB tax as a strategy to improve people's health'). Themes and subthemes from the systematic review and corresponding questionnaire items can be found in online Supplemental Table S1. Items were all phrased in the active voice, and responses were indicated on a seven-point Likert scale ranging from 1 'strongly disagree' to 7 'strongly agree'. For the descriptive statistics, the variables were grouped into three categories: 'disagree' (response options 1-3), 'neither' (response option 4) and 
'agree' (response options 5-7). The questionnaire items 'I believe that an SSB tax would reduce my SSB consumption' and 'I believe that an SSB tax would contribute to improving my health' also included the response option 'I do not drink SSB' because the two items were considered not applicable to people who do not drink SSB. Participants who selected this option were excluded from the analyses with these two items.

\section{Statistical analyses}

Participants reporting a body height of $<100 \mathrm{~cm}$ and/or SSB consumption of $>105$ glasses per week (i.e., $>3 \mathrm{l} / \mathrm{d}$ ) were excluded from all analyses ( $n$ 12), because these values were considered implausible. Descriptive statistics were used to characterise the sample, to determine the level of public acceptability of an SSB tax and to determine the level of agreement with beliefs about effectiveness, appropriateness, economic and socioeconomic benefit, policy adoption and implementation and trust. Associations between acceptability of an SSB tax and sociodemographic factors, weight status, SSB consumption and beliefs were assessed using linear regressions. Given the non-linear relationship between acceptability of an SSB tax and BMI and SSB consumption, BMI was categorised into underweight and normal weight $\left(<25 \mathrm{~kg} / \mathrm{m}^{2}\right)$, overweight $\left(25.0-29.9 \mathrm{~kg} / \mathrm{m}^{2}\right)$ and obese $\left(\geq 30 \mathrm{~kg} / \mathrm{m}^{2}\right)$, and SSB consumption was divided in tertiles. The three acceptability variables that measured the acceptability of an SSB tax were modelled as dependent variables. Multivariable linear regression models were produced with all sociodemographic factors, weight status and SSB consumption entered simultaneously as independent variables to assess which variables were independently associated with the acceptability of an SSB tax. Values of $P<0.05$ were considered statistically significant. Moreover, linear regressions were conducted to determine the associations between acceptability of an SSB tax and each belief variable separately, adjusted for sociodemographic factors, weight status and SSB consumption. Beliefs that appeared to have negative implications for the acceptability of an SSB tax in previously conducted studies were reverse-coded in the analyses ${ }^{(21)}$. Because of increased type I error rate caused by multiple comparisons (the probability of false-positive findings increases as the number of statistical tests increases), a Bonferroni-corrected $P$-value was used to test the statistical significance of belief variables $(P<0 \cdot 002)$. Statistical analyses were performed using IBM SPSS Statistics 25.0. All statistical tests were two-sided.

\section{Results}

The characteristics of participants are presented in Table 1. The distribution of sex, age, education level and location in
Table 1 Descriptive statistics of sociodemographic characteristics, weight status and sugar-sweetened beverage (SSB) consumption of participants ( $n$ 488)

\begin{tabular}{|c|c|c|}
\hline & $\begin{array}{l}n \text { or } \\
\text { mean }\end{array}$ & $\begin{array}{c}\% \text { or } \\
\text { SD }\end{array}$ \\
\hline \multicolumn{3}{|l|}{ Age (years), $n$ and \% } \\
\hline $18-24$ & 54 & $11 \cdot 1$ \\
\hline $25-54$ & 236 & $48 \cdot 4$ \\
\hline$\geq 55$ & 198 & $40 \cdot 6$ \\
\hline \multicolumn{3}{|l|}{ Sex, $n$ and \% } \\
\hline Male & 242 & 49.6 \\
\hline Female & 246 & $50 \cdot 4$ \\
\hline \multicolumn{3}{|l|}{ Education level, $n$ and $\%$} \\
\hline Low & 110 & $22 \cdot 5$ \\
\hline Moderate & 198 & $40 \cdot 6$ \\
\hline High & 180 & $36 \cdot 9$ \\
\hline \multicolumn{3}{|l|}{ Household composition, $n$ and $\%$} \\
\hline No children/adolescents & 346 & 70.9 \\
\hline One or more children ( $0-13$ years) & 66 & $13 \cdot 5$ \\
\hline One or more adolescents (14-18 years) & 76 & $15 \cdot 6$ \\
\hline \multicolumn{3}{|l|}{ Grocery responsibility, $n$ and $\%$} \\
\hline Not responsible & 14 & $2 \cdot 9$ \\
\hline Partly responsible & 115 & 23.6 \\
\hline Largely/totally responsible & 359 & 73.6 \\
\hline \multicolumn{3}{|l|}{ Employment status, $n$ and $\%$} \\
\hline Unemployed $\dagger$ & 234 & 48.0 \\
\hline Employed & 254 & $52 \cdot 0$ \\
\hline BMI $\left(\mathrm{kg} / \mathrm{m}^{2}\right)$, mean and SD & 25.8 & 4.9 \\
\hline \multicolumn{3}{|l|}{ Weight status, $n$ and $\%$} \\
\hline $\mathrm{BMI}<25 \mathrm{~kg} / \mathrm{m}^{2}$ & 230 & $47 \cdot 1$ \\
\hline Overweight & 180 & 36.9 \\
\hline Obese & 78 & $16 \cdot 0$ \\
\hline $\begin{array}{l}\text { SSB consumption (glasses per week), mean } \\
\text { and SD }\end{array}$ & $8 \cdot 3$ & $14 \cdot 7$ \\
\hline Regular soft drinks & $4 \cdot 1$ & $7 \cdot 1$ \\
\hline Fruit drinks and juices with added sugars & $2 \cdot 2$ & 4.7 \\
\hline Energy and sport drinks with added sugars & 0.8 & $3 \cdot 7$ \\
\hline Flavoured water with added sugars & $1 \cdot 2$ & 4.0 \\
\hline
\end{tabular}

*Including one or more adolecents aged 14-18 years and children of both age categories (i.e., $0-13$ and $14-18$ years) living at home.

†Including unemployed, retired, student, other.

the study sample was reflective of the distribution of those variables within the Dutch population based on data from the $\mathrm{CBS}^{(38)}$. Of the participants, $37 \%$ reported to be overweight and $16 \%$ reported to be obese, which is comparable with the overweight and obesity rates in the Netherlands (35 and $15 \%$, respectively) $)^{(33)}$. In addition, the mean consumption of SSB in our sample is comparable with that in the Dutch population (8.3 and 9.4 glasses per week, respectively) ${ }^{(34)}$.

An SSB tax in general and an SSB tax as a strategy to reduce overweight were supported by less than half of the participants ( 40 and $42 \%$, respectively) (Table 2). More than half (55\%) of the participants supported an SSB tax if revenue is used for health initiatives. The majority of participants believed that overweight is a problem in the Netherlands $(70 \%)$, that SSB consumption contributes to the development of overweight ( $81 \%)$, and that overweight is the responsibility of people themselves (90\%) and/or SSB producers ( $58 \%$ ). Less than half of participants believed that an SSB tax would reduce people's SSB consumption ( $43 \%)$. Of the participants who indicated 
Table 2 Descriptive statistics of acceptability of a sugar-sweetened beverage (SSB) tax and beliefs ( $n$ 488)

\begin{tabular}{|c|c|c|c|c|c|c|c|c|}
\hline & \multirow[b]{2}{*}{ Mean } & \multirow[b]{2}{*}{ SD } & \multicolumn{2}{|c|}{ Disagree } & \multicolumn{2}{|c|}{ Neither } & \multicolumn{2}{|c|}{ Agree } \\
\hline & & & $n$ & $\%$ & $n$ & $\%$ & $n$ & $\%$ \\
\hline \multicolumn{9}{|l|}{ Acceptability of an SSB tax } \\
\hline I support imposing an SSB tax & 3.7 & $2 \cdot 0$ & 212 & 43.4 & 82 & $16 \cdot 8$ & 194 & 39.8 \\
\hline I support imposing an SSB tax as a strategy to reduce overweight & 3.8 & $2 \cdot 0$ & 209 & $42 \cdot 8$ & 74 & $15 \cdot 2$ & 205 & $42 \cdot 0$ \\
\hline I support imposing an SSB tax if revenue is used for health initiatives & 4.4 & $2 \cdot 0$ & 155 & 31.8 & 67 & 13.7 & 266 & 54.5 \\
\hline \multicolumn{9}{|l|}{ Beliefs about effectiveness and cost-effectiveness } \\
\hline An SSB tax will be paid by consumers & $5 \cdot 1$ & 1.4 & 49 & $10 \cdot 0$ & 110 & 22.5 & 329 & 67.4 \\
\hline An SSB tax will encourage producers to reduce sugar in beverages & $4 \cdot 8$ & 1.5 & 80 & $16 \cdot 4$ & 100 & 20.5 & 308 & 63.1 \\
\hline SSB are more detrimental for health than artificially sweetened beverages & 4.6 & 1.6 & 94 & $19 \cdot 3$ & 137 & 28.1 & 257 & $52 \cdot 7$ \\
\hline An SSB tax will save healthcare costs in the future & 4.5 & 1.6 & 106 & $21 \cdot 7$ & 125 & $25 \cdot 6$ & 257 & $52 \cdot 7$ \\
\hline An SSB tax would contribute to improving people's health & 4.4 & 1.5 & 112 & $23 \cdot 0$ & 128 & $26 \cdot 2$ & 248 & $50 \cdot 8$ \\
\hline An SSB tax would contribute to improving my health* & 4.0 & 1.9 & 144 & 32.9 & 114 & $26 \cdot 0$ & 180 & $41 \cdot 1$ \\
\hline An SSB tax would reduce people's SSB consumption & $4 \cdot 0$ & 1.6 & 161 & 33.0 & 119 & 24.4 & 208 & $42 \cdot 6$ \\
\hline An SSB tax would reduce my SSB consumptiont & 3.9 & 1.9 & 156 & $36 \cdot 7$ & 108 & $25 \cdot 4$ & 161 & $37 \cdot 9$ \\
\hline An SSB tax will be paid by producers & 3.5 & 1.7 & 231 & $47 \cdot 3$ & 124 & $25 \cdot 4$ & 133 & $27 \cdot 3$ \\
\hline \multicolumn{9}{|l|}{ Beliefs about appropriateness } \\
\hline Overweight is the responsibility of people themselves & $6 \cdot 0$ & $1 \cdot 1$ & 15 & $3 \cdot 1$ & 33 & $6 \cdot 8$ & 440 & $90 \cdot 2$ \\
\hline SSB consumption contributes to the development of overweight & 5.4 & 1.3 & 32 & $6 \cdot 6$ & 63 & $12 \cdot 9$ & 393 & 80.5 \\
\hline Overweight is a problem in the Netherlands & $5 \cdot 0$ & 1.4 & 55 & $11 \cdot 3$ & 92 & $18 \cdot 9$ & 341 & 69.9 \\
\hline Overweight is the responsibility of SSB producers & 4.6 & 1.6 & 96 & $19 \cdot 7$ & 109 & $22 \cdot 3$ & 283 & 58.0 \\
\hline SSB should be more expensive than beverages without sugar & 4.5 & 1.9 & 137 & $28 \cdot 1$ & 91 & $18 \cdot 6$ & 260 & 53.3 \\
\hline An SSB tax limits individual freedom & 4.4 & 1.7 & 129 & $26 \cdot 4$ & 113 & 23.2 & 246 & $50 \cdot 4$ \\
\hline Overweight is the responsibility of the government & 3.3 & 1.6 & 258 & $52 \cdot 9$ & 106 & $21 \cdot 7$ & 124 & $25 \cdot 4$ \\
\hline \multicolumn{9}{|l|}{ Beliefs about economic and socioeconomic benefit } \\
\hline Raised revenue should be used for health care & $5 \cdot 3$ & 1.4 & 48 & $9 \cdot 8$ & 78 & $16 \cdot 0$ & 362 & $74 \cdot 2$ \\
\hline Raised revenue should be used for societal health programmes & 4.9 & 1.5 & 69 & $14 \cdot 1$ & 103 & $21 \cdot 1$ & 316 & 64.8 \\
\hline An SSB tax is not fair for low-income people & 4.3 & 1.8 & 140 & 28.7 & 118 & $24 \cdot 2$ & 230 & $47 \cdot 1$ \\
\hline An SSB tax has a negative economic impact & 3.6 & 1.5 & 207 & $42 \cdot 4$ & 165 & 33.8 & 116 & 23.8 \\
\hline Raised revenue should be used for the general budget & $2 \cdot 8$ & $1 \cdot 7$ & 294 & $60 \cdot 2$ & 109 & $22 \cdot 3$ & 85 & $17 \cdot 4$ \\
\hline \multicolumn{9}{|l|}{ Beliefs about policy adoption and implementation } \\
\hline \multirow{2}{*}{\multicolumn{9}{|c|}{$\begin{array}{l}\text { An SSB tax is teasidie to impiement in the INetnerianas } \\
\text { Trust }\end{array}$}} \\
\hline & & & & & & & & \\
\hline Public health experts give reliable information about the health risks of SSB & 4.7 & 1.4 & 74 & $15 \cdot 2$ & 143 & $29 \cdot 3$ & 271 & $55 \cdot 5$ \\
\hline The government views an SSB tax as a strategy to improve people's health & 4.0 & 1.6 & 153 & 31.4 & 131 & $26 \cdot 8$ & 204 & $41 \cdot 8$ \\
\hline SSB producers care about people's health & 3.4 & 1.7 & 241 & $49 \cdot 4$ & 126 & $25 \cdot 8$ & 121 & 24.8 \\
\hline
\end{tabular}

* $n 438$, not including sixty-two participants who responded 'I do not drink SSB'.

† $n$ 425, not including seventy-five participants who responded 'I do not drink SSB'.

consuming SSB, $38 \%$ believed that an SSB tax would reduce their own SSB consumption. Participants believed that an SSB tax will be paid by consumers (67\%), and felt that the raised revenue should be used for healthcare (74\%) and/or societal health programmes (65\%). Approximately half of participants believed that an SSB tax is not fair for those with a low income (47\%) and that an SSB tax limits individual freedom (50\%). Less than half of participants trusted that the government views an SSB tax as a strategy to improve people's health (42\%).

Participants with a high education level reported 0.82 point higher on the seven-point Likert scale for supporting an SSB tax in general, 0.71 point higher on supporting an SSB tax as a strategy to reduce overweight, and 0.70 point higher on supporting an SSB tax if revenue is used for health initiatives compared with participants with a low education level $(P<0.05)$ (Table 3$)$. Participants with a moderate education level were only more supportive of an SSB tax if revenue is used for health initiatives than those with a low education level $(P<0.05)$. Participants living at home with one or more adolescents were less supportive of an SSB tax as a strategy to reduce overweight or to use the revenue for health initiatives compared with those living at home without children or adolescents $(P<0.05)$. Participants with one or more children living at home did not have statistically significant different levels of support than those living at home without children or adolescents. Participants with overweight were less supportive of an SSB tax in general and as a strategy to reduce overweight compared with those with a BMI $<25 \mathrm{~kg} / \mathrm{m}^{2}(P<0.05)$. Participants with obesity did not have statistically significant different levels of support than those with a BMI $<25 \mathrm{~kg} / \mathrm{m}^{2}$. Participants with moderate or high SSB consumption were less supportive of SSB taxes, irrespective of the objective, than those with low SSB consumption $(P<0.05)$.

The majority of beliefs about effectiveness, appropriateness, socioeconomic and economic benefit, policy adoption and implementation and trust were statistically significant associated with the acceptability of an SSB tax (Table 4). For example, every point increase on the belief that an SSB tax reduces people's SSB consumption was associated with a 0.64 point increase on support for an SSB tax in general, adjusted for sociodemographic factors, 
Table 3 Associations between acceptability of a sugar-sweetened beverage (SSB) tax and sociodemographic factors, weight status and SSB consumption ( $n$ 488)

\begin{tabular}{|c|c|c|c|c|c|c|c|c|c|}
\hline & \multicolumn{3}{|c|}{ Support for an SSB tax† } & \multicolumn{3}{|c|}{$\begin{array}{c}\text { Support for an SSB tax as a } \\
\text { strategy to reduce overweight† }\end{array}$} & \multicolumn{3}{|c|}{$\begin{array}{l}\text { Support for an SSB tax if } \\
\text { revenue is used for health } \\
\text { initiatives } t\end{array}$} \\
\hline & $B$ & $95 \% \mathrm{Cl}$ & $P$ & $B$ & $95 \% \mathrm{Cl}$ & $P$ & $B$ & $95 \% \mathrm{Cl}$ & $P$ \\
\hline \multicolumn{10}{|l|}{ Age (years) } \\
\hline $18-24$ & & Ref. & & & Ref. & & & Ref. & \\
\hline $25-54$ & 0.03 & $-0.64,0.70$ & 0.929 & -0.15 & $-0.83,0.52$ & 0.659 & -0.24 & $-0.93,0.45$ & 0.495 \\
\hline$\geq 55$ & 0.12 & $-0.58,0.82$ & 0.737 & -0.13 & $-0.83,0.57$ & 0.716 & -0.25 & $-0.97,0.46$ & 0.486 \\
\hline \multicolumn{10}{|l|}{ Sex } \\
\hline Male & & Ref. & & & Ref. & & & Ref. & \\
\hline Female & -0.22 & $-0.62,0.18$ & 0.276 & -0.14 & $-0.54,0.27$ & 0.505 & -0.37 & $-0.78,0.04$ & 0.078 \\
\hline \multicolumn{10}{|l|}{ Education level } \\
\hline Low & & Ref. & & & Ref. & & & Ref. & \\
\hline Moderate & 0.40 & $-0.07,0.87$ & 0.096 & 0.33 & $-0.14,0.80$ & 0.166 & 0.52 & $0.03,1.00$ & $0.036^{*}$ \\
\hline High & 0.82 & $0.32,1.31$ & $0.001^{*}$ & 0.71 & $0.21,1.20$ & $0.005^{*}$ & 0.70 & $0.19,1 \cdot 20$ & $0.007^{*}$ \\
\hline \multicolumn{10}{|l|}{ Household composition } \\
\hline No children/adolescents & & Ref. & & & Ref. & & & Ref. & \\
\hline Children ( $0-13$ years) & -0.02 & $-0.59,0.54$ & 0.936 & 0.05 & $-0.52,0.61$ & 0.873 & -0.09 & $-0.67,0.49$ & 0.767 \\
\hline Adolescents (14-18 years) & -0.49 & $-1.00,0.03$ & 0.067 & -0.57 & $-1.09,-0.05$ & $0.033^{*}$ & -0.56 & $-1.09,-0.02$ & $0.040^{*}$ \\
\hline \multicolumn{10}{|l|}{ Grocery responsibility } \\
\hline Not responsible & & Ref. & & & Ref. & & & Ref. & \\
\hline Partly responsible & -0.58 & $-1.67,0.51$ & 0.296 & -0.20 & $-1.30,0.90$ & 0.724 & -0.02 & $-1 \cdot 14,1 \cdot 11$ & 0.973 \\
\hline Largely/totally responsible & -0.60 & $-1.68,0.47$ & 0.273 & -0.32 & $-1.40,0.77$ & 0.567 & -0.04 & $-1.15,1.06$ & 0.939 \\
\hline \multicolumn{10}{|l|}{ Employment status } \\
\hline Unemployed & & Ref. & & & Ref. & & & Ref. & \\
\hline Employed & -0.05 & $-0.46,0.37$ & 0.832 & -0.09 & $-0.51,0.34$ & 0.692 & -0.25 & $-0.68,0.18$ & 0.261 \\
\hline \multicolumn{10}{|l|}{ Weight status } \\
\hline $\mathrm{BMI}<25 \mathrm{~kg} / \mathrm{m}^{2}$ & & Ref. & & & Ref. & & & Ref. & \\
\hline Overweight & -0.49 & $-0.89,-0.09$ & $0.017^{*}$ & -0.52 & $-0.92,-0.12$ & $0.012^{*}$ & -0.36 & $-0.78,0.05$ & 0.086 \\
\hline Obese & -0.35 & $-0.87,0.17$ & 0.189 & -0.44 & $-0.96,0.09$ & 0.102 & -0.32 & $-0.86,0.22$ & 0.240 \\
\hline \multicolumn{10}{|l|}{ SSB consumption } \\
\hline Low & & Ref. & & & Ref. & & & Ref. & \\
\hline Moderate & -0.86 & $-1 \cdot 30,-0.43$ & $<0.001^{*}$ & -0.83 & $-1 \cdot 27,-0.39$ & $<0.001^{*}$ & -0.60 & $-1 \cdot 05,-0.15$ & $0.009^{*}$ \\
\hline High & -1.01 & $-1.47,-0.56$ & $<0.001^{\star}$ & -0.84 & $-1 \cdot 29,-0.38$ & $<0.001^{\star}$ & -0.91 & $-1 \cdot 38,-0.45$ & $<0.001^{*}$ \\
\hline
\end{tabular}

$B$, regression coefficient

Multivariable analysis with all independent variables entered simultaneously. ${ }^{*} P<0.05$.

†Measured on a seven-point Likert scale ranging from 1 'strongly disagree' to 7 'strongly agree'.

weight status and SSB consumption. The beliefs 'an SSB tax will be paid by consumers', 'overweight is the responsibility of people themselves' and 'SSB producers care about people's health' were not statistically significantly associated with the acceptability of an SSB tax (Table 4).

\section{Discussion}

The current study aimed to determine the level of public acceptability of an SSB tax and assess its associated factors. We demonstrated that $40 \%$ of participants supported $(v$. $43 \%$ who opposed) an SSB tax in general, $42 \%$ supported (v. $43 \%$ who opposed) an SSB tax as a strategy to reduce overweight and $55 \%$ supported ( $v .32 \%$ who opposed) an SSB tax if revenue is used for health initiatives. Participants with a high education level were more supportive of the tax than those with a low education level. Participants with overweight, moderate or high SSB consumption and those with adolescents living at home were less supportive of the tax than those with a BMI $<25 \mathrm{~kg} / \mathrm{m}^{2}$, low SSB consumption and no children or adolescents living at home. Moreover, participants were more supportive of an SSB tax when they more strongly believed that an SSB tax is effective, is appropriate, has socioeconomic and economic benefit and is feasible to implement; and when they had more trust in the government and public health experts.

The finding that the level of public acceptability of an SSB tax tends to depend on the intended objective of the tax is in line with the findings of a systematic review and meta-analysis about public acceptability of an SSB $\operatorname{tax}^{(21)}$. In this meta-analysis based on studies conducted in the USA, Australia, the UK and France, pooled proportions indicated that $42 \%$ of the public supports an SSB tax in general, $39 \%$ of the public supports an SSB tax as a strategy to reduce overweight and obesity and $66 \%$ of the public supports an SSB tax if revenue is used for health initiatives ${ }^{(21)}$. These findings suggest that higher public acceptability for an SSB tax if revenue is used for health initiatives can be observed regardless of the study population (i.e., is not country-specific). 


\begin{tabular}{|c|c|c|c|c|c|c|c|c|c|}
\hline & \multicolumn{3}{|c|}{ Support for an SSB tax† } & \multicolumn{3}{|c|}{$\begin{array}{l}\text { Support for an SSB tax as a } \\
\text { strategy to reduce overweight† }\end{array}$} & \multicolumn{3}{|c|}{$\begin{array}{l}\text { Support for an SSB tax if revenue } \\
\text { is used for health initiatives } †\end{array}$} \\
\hline & $B$ & $95 \% \mathrm{Cl}$ & $P$ & $B$ & $95 \% \mathrm{Cl}$ & $P$ & $B$ & $95 \% \mathrm{Cl}$ & $P$ \\
\hline \multicolumn{10}{|l|}{ Beliefs about effectiveness and cost-effectiveness } \\
\hline An SSB tax would contribute to improving people's health & 0.72 & $0.62,0.81$ & $<0.001^{*}$ & 0.77 & $0.70,0.86$ & $<0.001^{*}$ & 0.76 & $0.66,0.85$ & $<0.001^{*}$ \\
\hline An SSB tax would reduce people's SSB consumption & 0.64 & $0.55,0.74$ & $<0.001^{*}$ & 0.70 & $0.61,0.79$ & $<0.001^{*}$ & 0.64 & $0.54,0.73$ & $<0.001^{*}$ \\
\hline An SSB tax will save healthcare costs in the future & 0.61 & $0.51,0.71$ & $<0.001^{*}$ & 0.63 & $0.53,0.73$ & $<0.001^{*}$ & 0.66 & $0.56,0.76$ & $<0.001^{*}$ \\
\hline An SSB tax will encourage producers to reduce sugar in beverages & $0 \cdot 61$ & $0.50,0.71$ & $<0.001^{*}$ & 0.59 & $0.48,0.70$ & $<0.001^{*}$ & 0.61 & $0.50,0.72$ & $<0.001^{*}$ \\
\hline SSB are more detrimental for health than artificially sweetened beverages & 0.47 & $0.37,0.58$ & $<0.001^{*}$ & 0.49 & $0.39,0.60$ & $<0.001^{*}$ & 0.41 & $0.30,0.52$ & $<0.001^{*}$ \\
\hline An SSB tax would contribute to improving my health $\ddagger$ & 0.46 & $0.38,0.55$ & $<0.001^{*}$ & 0.48 & $0.39,0.57$ & $<0.001^{*}$ & 0.47 & $0.38,0.56$ & $<0.001^{*}$ \\
\hline An SSB tax would reduce my SSB consumption§ & 0.39 & $0.30,0.48$ & $<0.001^{*}$ & 0.42 & $0.33,0.51$ & $<0.001^{*}$ & 0.44 & $0.34,0.53$ & $<0.001^{*}$ \\
\hline An SSB tax will be paid by producers & 0.21 & $0.11,0.31$ & $<0.001^{*}$ & 0.22 & $0.12,0.32$ & $<0.001^{*}$ & $0 \cdot 16$ & $0.05,0.26$ & 0.003 \\
\hline An SSB tax will be paid by consumers & 0.06 & $-0.06,0.19$ & 0.323 & 0.02 & $-0.10,0.15$ & 0.708 & 0.09 & $-0.04,0.22$ & 0.176 \\
\hline \multicolumn{10}{|l|}{ Beliefs about appropriateness } \\
\hline SSB should be more expensive than beverages without sugar & 0.72 & $0.65,0.80$ & $<0.001^{*}$ & 0.73 & $0.65,0.80$ & $<0.001^{*}$ & 0.70 & $0.62,0.78$ & $<0.001^{*}$ \\
\hline SSB consumption contributes to the development of overweight & 0.65 & $0.52,0.77$ & $<0.001^{*}$ & 0.65 & $0.52,0.78$ & $<0.001^{*}$ & 0.68 & $0.55,0.82$ & $<0.001^{*}$ \\
\hline Overweight is a problem in the Netherlands & 0.61 & $0.50,0.73$ & $<0.001^{*}$ & 0.61 & $0.49,0.73$ & $<0.001^{*}$ & 0.60 & $0.48,0.72$ & $<0.001^{*}$ \\
\hline Overweight is the responsibility of SSB producers & 0.53 & $0.43,0.63$ & $<0.001^{*}$ & 0.52 & $0.42,0.62$ & $<0.001^{*}$ & 0.49 & $0.38,0.59$ & $<0.001^{*}$ \\
\hline An SSB tax limits individual freedom\| & 0.48 & $0.39,0.58$ & $<0.001^{*}$ & 0.50 & $0.40,0.59$ & $<0.001^{*}$ & 0.49 & $0.39,0.58$ & $<0.001^{*}$ \\
\hline Overweight is the responsibility of the government & 0.43 & $0.32,0.53$ & $<0.001^{*}$ & 0.45 & $0.34,0.56$ & $<0.001^{*}$ & 0.37 & $0.26,0.49$ & $<0.001^{*}$ \\
\hline Overweight is the responsibility of people themselves $\|$ & -0.07 & $-0.24,0.09$ & 0.384 & -0.07 & $-0.24,0.10$ & 0.408 & -0.23 & $-0.40,-0.06$ & 0.010 \\
\hline \multicolumn{10}{|l|}{ Beliefs about economic and socioeconomic benefit } \\
\hline Raised revenue should be used for societal health programmes & 0.48 & $0.37,0.60$ & $<0.001^{*}$ & 0.52 & $0.41,0.63$ & $<0.001^{*}$ & 0.57 & $0.46,0.68$ & $<0.001^{*}$ \\
\hline Raised revenue should be used for healthcare & 0.41 & $0.29,0.53$ & $<0.001^{*}$ & 0.43 & $0.31,0.55$ & $<0.001^{*}$ & 0.57 & $0.45,0.69$ & $<0.001^{*}$ \\
\hline An SSB tax is not fair for those with a low income\| & 0.41 & $0.32,0.51$ & $<0.001^{*}$ & 0.40 & $0.30,0.49$ & $<0.001^{*}$ & 0.41 & $0.31,0.51$ & $<0.001^{*}$ \\
\hline Raised revenue should be used for the general budget & 0.27 & $0.17,0.38$ & $<0.001^{*}$ & 0.29 & $0.19,0.40$ & $<0.001^{*}$ & $0 \cdot 17$ & $0.06,0.28$ & $0.002^{*}$ \\
\hline An SSB tax has a negative economic impact $\|$ & 0.15 & $0.03,0.27$ & 0.012 & 0.18 & $0.06,0.30$ & 0.004 & 0.22 & $0.10,0.35$ & $<0.001^{*}$ \\
\hline \multicolumn{10}{|l|}{ Beliefs about policy adoption and implementation } \\
\hline An SSB tax is feasible to implement in the Netherlands & 0.67 & $0.58,0.76$ & $<0.001^{*}$ & 0.68 & $0.59,0.76$ & $<0.001^{*}$ & 0.68 & $0.58,0.77$ & $<0.001^{*}$ \\
\hline \multicolumn{10}{|l|}{ Trust } \\
\hline Public health experts give reliable information about the health risks of SSB & 0.52 & $0.40,0.63$ & $<0.001^{*}$ & 0.55 & $0.44,0.67$ & $<0.001^{*}$ & 0.62 & $0.51,0.74$ & $<0.001^{*}$ \\
\hline The government views an SSB tax as a strategy to improve people's health & 0.47 & $0.36,0.57$ & $<0.001^{*}$ & 0.49 & $0.39,0.59$ & $<0.001^{*}$ & 0.45 & $0.34,0.55$ & $<0.001^{*}$ \\
\hline SSB producers care about people's health $\|$ & -0.07 & $-0.17,0.04$ & 0.220 & -0.03 & $-0.13,0.08$ & 0.612 & -0.03 & $-0.14,0.08$ & 0.592 \\
\hline
\end{tabular}

$B$, regression coefficient.

All analyses were adjusted for age, sex, education level, weight status, SSB consumption, household composition, grocery responsibility and employment status

${ }^{*} P<0.002$.

†Measured on a seven-point Likert scale ranging from 1 'strongly disagree' to 7 'strongly agree'.

†n 438, not including participants who responded 'I do not drink SSB'.

\$n 425, not including participants who responded 'I do not drink SSB'.

\|Reverse-coded items. 
Consistent with previously conducted studies in the USA, Australia and France ${ }^{(23-27)}$, we found that adults with a high education level are more supportive of an SSB tax than those with a low education level. However, our finding that adults with adolescents living at home are less supportive of an SSB tax is not consistent with the results reported by Julia et al. ${ }^{(25)}$. Julia et al $^{(25)}$ observed no statistically significant association between household composition and public acceptability of an SSB tax among French adults. A potential reason for this discrepancy could be the higher consumption of SSB among Dutch adolescents than among French adolescents ${ }^{(34,41)}$. Participants in our study with adolescents living at home may be less supportive of the tax because of an expected increase in grocery spending. Although we assessed the participants' own SSB consumption, we have no information on the consumption of household members or purchases. Therefore, we were unable to test our hypothesis.

The finding that adults with overweight and obesity are less supportive of an SSB tax than those with a BMI $<25 \mathrm{~kg} / \mathrm{m}^{2}$, although the negative association between obesity and acceptability of an SSB tax was not statistically significant, is not in line with previously conducted studies in the USA, Australia and the UK that observed no statistically significant associations between weight status and public acceptability of an SSB tax ${ }^{(23,27,28)}$. Rivard et al. ${ }^{(26)}$ demonstrated that the likelihood of support for an SSB tax is statistically significantly lower among US adults with obesity than among those with a BMI $<25 \mathrm{~kg} / \mathrm{m}^{2}$. A potential reason for the non-significant association between obesity and acceptability in our study could be due to a lack of statistical power. Comparable with the distribution of obesity within the Dutch population ${ }^{(33)}, 16 \%$ of participants $(n 78)$ in our sample reported to be obese, while corresponding with the higher obesity rates in the USA, more participants reported to be obese $(29 \%, n 161)$ in the study by Rivard et al. ${ }^{(26)}$. The finding that adults with moderate or high SSB consumption are less supportive of an SSB tax than those with low SSB consumption is consistent with the results reported by Donaldson et al. ${ }^{(24)}$. Donaldson et $a l^{(24)}$ demonstrated that the likelihood of support for an SSB tax is lower among adults from a mid-Atlantic US state who consume SSB daily. In contrast to our results, SSB consumption was not associated with the acceptability of an SSB tax among French adults ${ }^{(25)}$. Julia et $a l .{ }^{(25)}$ indicated that sociodemographic factors have been associated with SSB consumption and that these sociodemographic factors rather than SSB consumption itself were associated with the acceptability of an SSB tax. Although we have adjusted our models for sociodemographic factors, SSB consumption was independently associated with the acceptability of an SSB tax in our study.

We found no statistically significant associations for age, sex, grocery responsibility and employment status. Inconsistent results have been reported in the existing literature regarding age and sex. A potential reason for this inconsistency could be that these associations may vary across countries. With regard to age, younger participants were more likely to support the tax than older participants in studies conducted among US ${ }^{(26,27,30,31)}$ and Australian adults ${ }^{(23)}$. In contrast, older participants were more supportive of the tax than younger participants in the French sample ${ }^{(25)}$. In line with our findings, other studies conducted in the USA and the UK report no statistically significant association between age and acceptability of an SSB $\operatorname{tax}^{(24,28)}$. With regard to sex, females were more supportive of the tax than males in studies conducted among US ${ }^{(24,30)}$ and Australian adults ${ }^{(23,29)}$. In line with our findings, sex was not statistically significantly associated with the public acceptability of an SSB tax in other studies conducted in the $\mathrm{USA}^{(26-28,31)}$, France ${ }^{(25)}$ and the UK ${ }^{(28)}$. No previous evidence is reported regarding the associations between acceptability of an SSB tax and grocery responsibility and employment status.

\section{Strengths and limitations}

The main strength of the current study is that it is, to our knowledge, the first that investigated public acceptability of an SSB tax in relation to a wide range of factors, including the majority of beliefs that appeared to have implications for the acceptability of an SSB tax in previously conducted qualitative studies. Furthermore, we used a nationally representative sample of the Dutch population for age, sex, education level and location. The current study also has several limitations. Firstly, data were self-reported and may, therefore, be prone to social desirability bias. Additionally, BMI could have been underreported because of self-reporting ${ }^{(42)}$. However, in our sample, $40 \%$ of participants reported to be overweight and $16 \%$ obese, which is comparable with the overweight and obesity rates in the Netherlands (35 and $15 \%$, respectively) ${ }^{(33)}$. Secondly, it is unknown whether non-respondents would have provided different answers to our survey questionnaire than those included in the sample. However, the acceptability of an SSB tax is comparable with previously conducted studies, which increases confidence in our findings. Thirdly, although previously conducted studies showed education level to be associated with the acceptability of an SSB tax rather than income ${ }^{(23-26,28,30)}$, one study found lower support for an SSB tax among those with a higher income ${ }^{(27)}$. We have no data on income in the current study to investigate this in the Netherlands. Lastly, there is controversy surrounding how data derived from Likert scales should be analysed. However, Likert scale items with at least five categories may generally be treated as continuous data ${ }^{(43)}$.

\section{Implications for future research}

Different SSB tax definitions, questions, response options and data collection methods have been used in the literature to assess public acceptability of an SSB tax, which all may have influenced responses. Multi-country surveys are 
needed to enable high-quality cross-country comparisons. Since the literature on public acceptability of an SSB tax in low- and middle-income countries is scarce ${ }^{(21)}$, low- and middle-income countries should be included in these surveys. Furthermore, future longitudinal and experimental studies should explore how to change public acceptability of an SSB tax and its associated beliefs. Our data were crosssectional, and therefore causality was not determined in the current study. In addition, the stage of implementation of an SSB tax itself may be an important determinant of public acceptability of an SSB tax. Public acceptability of government interventions to change health-related behaviours generally becomes more acceptable once they have been introduced ${ }^{(20)}$. We were not able to investigate this relation because no SSB tax was implemented in the Netherlands during our study period. If an SSB tax will be implemented in the Netherlands in the future, we encourage replication of our study to generate insights into the relationship between implementation and public acceptability of an SSB tax. Another potential direction for future research lies in investigating public acceptability of other environmental interventions on the consumption of SSB (e.g., limits to the availability of SSB in schools and multicomponent community campaigns focusing on SSB) ${ }^{(6)}$ and of other healthrelated food tax options (e.g., taxes on junk food).

\section{Implications for practice}

The current study provides insights into the current public acceptability of an SSB tax that could have implications on policymaking in the Netherlands. For example, our finding that the majority of the Dutch public supports an SSB tax if revenue is used for health initiatives may affect agenda-setting of the policy ${ }^{(20)}$. Although an SSB tax has been (and is currently being) discussed in the Netherlands, the level of public acceptability of an SSB tax has received little attention in the political debate. However, it is important to note that public acceptability is only one factor in the dynamic and complex system in which the policymaking process takes place ${ }^{(44)}$. Other important factors, such as changes in government, industry opposition and administrative load for the tax authority ${ }^{(45)}$, may affect the policymaking process as well.

We demonstrated that support for an SSB tax if revenue is used for health initiatives is higher than support for an SSB tax in general, which suggests, in line with the review by Eykelenboom et $a l .{ }^{(21)}$, that raising the revenue for health initiatives could elicit increased public acceptability. Currently, some countries invest the revenue raised by SSB taxation in health initiatives. For example, the revenue collected from the Soft Drinks Industry Levy in the UK is invested in programmes to encourage children's physical activity ${ }^{(46)}$. Because of increased public acceptability across countries if tax revenue is used for health initiatives, it should be considered to recommend the use of SSB tax revenue for health initiatives in global guidelines for SSB taxes. When explicit earmarking of revenues is not acceptable or feasible due to the political context of a country, other methods could be considered. For example, in the Netherlands, explicit earmarking of revenues may not be acceptable because of national budget rules ${ }^{(47)}$. However, a budget allocation specifically for health initiatives could be announced simultaneously with an SSB tax without explicitly linking SSB tax revenues ${ }^{(48)}$.

Targeting population subgroups with low levels of support for an SSB tax might be an effective strategy for campaigns ${ }^{(49)}$. In the Netherlands, we demonstrated that adults with a low education level, overweight, moderate or high SSB consumption and those with adolescents living at home may have low levels of support. Understanding the interests and characteristics of those groups allows customisation of messages ${ }^{(49)}$. For example, when targeting those with a low education level, messages could be adjusted according to their level of health literacy by providing messages at a low reading level and using pictures to facilitate understanding of information ${ }^{(50)}$. Our findings suggest that dissemination of messages around the following themes might be helpful: (i) effectiveness and cost-effectiveness (e.g., communicating about the potential effectiveness of an SSB tax in improving health, product reformulation and the potential cost-effectiveness of the tax in saving future healthcare costs), (ii) appropriateness (e.g., communicating about the relationship between obesity and SSB, the problem of overweight and the responsibility of entities external to individuals), (iii) economic and socioeconomic benefit (e.g., communicating about the potential of an SSB tax to raise revenue for societal health programmes and to limit socioeconomic inequalities in health), (iv) policy adoption and implementation (e.g., communicating about the feasibility of the introduction of an SSB tax) and (v) trust (e.g., communicating about the purpose of an SSB tax to improve population health).

\section{Conclusions}

In the Netherlands, an SSB tax in general is supported by less than half of the public. More than half of the public supports an SSB tax if revenue is used for health initiatives. Sociodemographic factors, weight status, SSB consumption and several beliefs about effectiveness, appropriateness, socioeconomic and economic benefit, policy adoption and implementation and trust are associated with public acceptability of an SSB tax and should therefore be taken into consideration in the introduction of such a policy.

\section{Acknowledgements}

Acknowledgements: The authors would like to thank Leon van Dam for his assistance in the design and conduct of the study. Financial support: The PEN (Policy Evaluation Network) project is funded by the Joint Programming 
Initiative 'A Healthy Diet for a Healthy Life' (JPI HDHL), a research and innovation initiative of EU member-states and associated countries. The funding agencies supporting the current work are (in alphabetical order of participating countries): France: Institut National de la Recherche Agronomique (INRA); Germany: Federal Ministry of Education and Research (BMBF); Ireland: Health Research Board (HRB); Italy: Ministry of Education, University and Research (MIUR); The Netherlands: The Netherlands Organisation for Health Research and Development (ZonMw), project no. 529051020; New Zealand: The University of Auckland, School of Population Health; Norway: The Research Council of Norway (RCN); Poland: The National Centre for Research and Development (NCBR). Conflict of interest: There are no conflicts of interest. Authorship: M.E. formulated the research question, designed and conducted the study, analysed the data, drafted the manuscript and made revisions based on feedback. M.M.v.S., M.R.O., C.M.R. and I.H.M.S. contributed to the formulation of the research question and design of the study, and critically reviewed the manuscript. All authors approved the final version of the manuscript submitted. Ethics of buman subject participation: The study was conducted according to the guidelines laid down in the Declaration of Helsinki. In accordance with the Dutch Medical Research Involving Human Subjects Act, approval of the study by a Medical Ethics Committee was not required. All participants provided informed consent, after having read the study information, by clicking to proceed with the survey.

\section{Supplementary material}

For supplementary material accompanying this article, please visit https://doi.org/10.1017/S1368980020001500

\section{References}

1. World Health Organization (2018) Factsheet Overweight and Obesity. https://www.who.int/news-room/fact-sheets/detail/ obesity-and-overweight (accessed January 2020).

2. Hu FB (2008) Obesity Epidemiology. Oxford: Oxford University Press.

3. Hu FB (2013) Resolved: there is sufficient scientific evidence that decreasing sugar-sweetened beverage consumption will reduce the prevalence of obesity and obesity-related diseases. Obes Rev 14, 606-619.

4. Malik VS, Pan A, Willett WC et al. (2013) Sugar-sweetened beverages and weight gain in children and adults: a systematic review and meta-analysis. Am J Clin Nutr 98, 1084-1102.

5. Woodward-Lopez G, Kao J \& Ritchie L (2011) To what extent have sweetened beverages contributed to the obesity epidemic? Public Health Nutr 14, 499-509.

6. von Philipsborn P, Stratil JM, Burns J et al. (2019) Environmental interventions to reduce the consumption of sugar-sweetened beverages and their effects on health. Cochrane Database Syst Rev 6, CD012292.
7. World Health Organization (2016) Report of the Commission on Ending Childhood Obesity. Geneva: WHO.

8. Nakhimovsky SS, Feigl AB, Avila C et al. (2016) Taxes on sugar-sweetened beverages to reduce overweight and obesity in middle-income countries: a systematic review. PLoS One 11, e0163358.

9. Thow AM, Downs S \& Jan S (2014) A systematic review of the effectiveness of food taxes and subsidies to improve diets: understanding the recent evidence. Nutr Rev 72, 551-565.

10. Cabrera Escobar MA, Veerman JL, Tollman SM et al. (2013) Evidence that a tax on sugar sweetened beverages reduces the obesity rate: a meta-analysis. BMC Public Health 13, 1072.

11. Powell LM, Chriqui JF, Khan T et al. (2013) Assessing the potential effectiveness of food and beverage taxes and subsidies for improving public health: a systematic review of prices, demand and body weight outcomes. Obes Rev 14, $110-128$.

12. Teng AM, Jones AC, Mizdrak A et al. (2019) Impact of sugarsweetened beverage taxes on purchases and dietary intake: systematic review and meta-analysis. Obes Rev 20, 1187-1204.

13. Basu S, Vellakkal S, Agrawal S et al. (2014) Averting obesity and type 2 diabetes in India through sugar-sweetened beverage taxation: an economic-epidemiologic modeling study. PLoS Med 11, e1001582.

14. Long MW, Gortmaker SL, Ward ZJ et al. (2015) Cost effectiveness of a sugar-sweetened beverage excise tax in the U.S. Am J Prev Med 49, 112-123.

15. Briggs AD, Mytton OT, Kehlbacher A et al. (2013) Overall and income specific effect on prevalence of overweight and obesity of $20 \%$ sugar sweetened drink tax in UK: econometric and comparative risk assessment modelling study. BMJ 347, f6189.

16. Briggs AD, Mytton OT, Madden D et al. (2013) The potential impact on obesity of a $10 \%$ tax on sugar-sweetened beverages in Ireland, an effect assessment modelling study. BMC Public Health 13, 860.

17. Schwendicke F \& Stolpe M (2017) Taxing sugar-sweetened beverages: impact on overweight and obesity in Germany. BMC Public Health 17, 88.

18. Manyema M, Veerman LJ, Chola L et al. (2014) The potential impact of a $20 \%$ tax on sugar-sweetened beverages on obesity in South African adults: a mathematical model. PLoS One 9, e105287.

19. World Cancer Research Fund International (2019) Nourishing Framework: Use Economic Tools to Address Food Affordability and Purchase Incentives. London: WCRF International.

20. Diepeveen S, Ling T, Suhrcke M et al. (2013) Public acceptability of government intervention to change health-related behaviours: a systematic review and narrative synthesis. BMC Public Health 13, 756.

21. Eykelenboom M, Stralen MM, Olthof MR et al. (2019) Political and public acceptability of a sugar-sweetened beverages tax: a mixed-method systematic review and metaanalysis. Int J Behav Nutr Phys Act 16, 78.

22. Brock C \& Kelly KJ (2017) Pennies for pounds: soda consumption and taxation as a test of self-interested voting behavior. World Med Health Policy 9, 418-434.

23. Sainsbury E, Hendy C, Magnusson R et al. (2018) Public support for government regulatory interventions for overweight and obesity in Australia. BMC Public Health 18, 513.

24. Donaldson EA, Cohen JE, Rutkow L et al. (2015) Public support for a sugar-sweetened beverage tax and pro-tax messages in a Mid-Atlantic US state. Public Health Nutr 18, 2263-2273.

25. Julia C, Mejean C, Vicari F et al. (2015) Public perception and characteristics related to acceptance of the sugar-sweetened beverage taxation launched in France in 2012. Public Health Nutr 18, 2679-2688. 
26. Rivard C, Smith D, McCann SE et al. (2012) Taxing sugarsweetened beverages: a survey of knowledge, attitudes and behaviours. Public Health Nutr 15, 1355-1361.

27. Gollust SE, Barry CL \& Niederdeppe J (2014) Americans' opinions about policies to reduce consumption of sugarsweetened beverages. Prev Med 63, 52-57.

28. Petrescu DC, Hollands GJ, Couturier DL et al. (2016) Public acceptability in the UK and USA of nudging to reduce obesity: the example of reducing sugar-sweetened beverages consumption. PLoS One 11, e0155995.

29. Farrell LC, Moore VM, Warin MJ et al. (2019) Why do the public support or oppose obesity prevention regulations? Results from a South Australian population survey. Health Promot J Austr 30, 47-59.

30. Curry LE, Rogers T, Williams P et al. (2018) Public attitudes and support for a sugar-sweetened beverage tax in America's heartland. Health Promot Pract 19, 418-426.

31. Wolfson JA, Gollust SE, Niederdeppe J et al. (2015) The role of parents in public views of strategies to address childhood obesity in the United States. Milbank Q 93, 73-111.

32. Morley B, Martin J, Niven P et al. (2012) Public opinion on food-related obesity prevention policy initiatives. Health Promot J Austr 23, 86-91.

33. Volksgezondheidszorg.info (2019) Overgewicht volwassenen. https://www.volksgezondheidenzorg.info/onderwerp/ overgewicht/cijfers-context/huidige-situatie\#node-overgewichtvolwassenen (accessed October 2019).

34. Rijksinstituut voor Volksgezondheid en Milieu (2018) Voedselconsumptiepeiling. https://www.rivm.nl/voedsel consumptiepeiling (accessed October 2019).

35. Ministry of Health, Welfare and Sport (2019) The National Prevention Agreement. Den Haag: Ministry of Health, Welfare and Sport.

36. Belastingdienst (2019) VAT tariffs. https://www. belastingdienst.nl/wps/wcm/connect/bldcontenten/ belastingdienst/business/vat/vat_in_the_netherlands/ calculating_vat/vat_tariffs (accessed February 2019).

37. Belastingdienst (2019) Particulars for goods liable to consumer tax. https://www.belastingdienst.nl/wps/wcm/connect/ bldcontenten/belastingdienst/customs/excise_duty_and_ consumer_tax/excise_duty_and_consumer_tax/particulars_ for_goods_liable_consumer_tax/ (accessed January 2020).
38. Centraal Bureau voor de Statistiek (2019) Centraal Bureau voor de Statistiek. https://www.cbs.nl/ (accessed February 2019).

39. BureauTaal (2019) BureauTaal. https://www.bureautaal.nl/ (accessed February 2019).

40. Beukers MH, Dekker LH, de Boer EJ et al. (2015) Development of the HELIUS food frequency questionnaires: ethnic-specific questionnaires to assess the diet of a multiethnic population in The Netherlands. Eur J Clin Nutr 69, 579-584.

41. European Food Safety Authority (2018) The EFSA Comprehensive European Food Consumption Database. https:// www.efsa.europa.eu/en/food-consumption/comprehensivedatabase (accessed October 2019).

42. Visscher TL, Viet AL, Kroesbergen IH et al. (2006) Underreporting of BMI in adults and its effect on obesity prevalence estimations in the period 1998 to 2001. Obesity (Silver Spring) 14, 2054-2063.

43. Harpe SE (2015) How to analyze Likert and other rating scale data. Curr Pharm Teach Learn 7, 836-850.

44. Weible CM \& Sabatier PA (2017) Theories of the Policy Process. Abingdon: Taylor \& Francis Inc.

45. Signal LN, Watts C, Murphy C et al. (2018) Appetite for health-related food taxes: new Zealand stakeholder views. Health Promot Int 33, 791-800.

46. GOV.UK (2019) Sugar tax revenue helps tackle childhood obesity. https://www.gov.uk/government/news/sugartax-revenue-helps-tackle-childhood-obesity (accessed October 2019).

47. Rijksoverheid (2017) Bijlage 1 bij startnota - Begrotingregels 2018-2022. https://www.rijksoverheid.nl/documenten/ kamerstukken/2017/11/03/bijlage-1-bij-startnota-\%E2 \%80 \%93begrotingsregels-2018-2022 (accessed January 2020).

48. Hagenaars LL, Jeurissen PPT \& Klazinga NS (2017) The taxation of unhealthy energy-dense foods (EDFs) and sugarsweetened beverages (SSBs): an overview of patterns observed in the policy content and policy context of 13 case studies. Health Policy 121, 887-894.

49. Schmid KL, Rivers SE, Latimer AE et al. (2008) Targeting or tailoring? Mark Health Serv 28, 32-37.

50. Thompson T (2014) Encyclopedia of Health Communication. London: SAGE Publications, Inc. 